\title{
SOCIALIZAÇÃO ORGANIZACIONAL: ESTUDO COMPARATIVO ENTRE SERVIDORES PÚBLICOS BRASILEIROS E NORUEGUESES
}

\author{
Virgínia Donizete de Carvalho \\ virginiadcarvalho@gmail.com \\ Universidade Federal de Alfenas - Varginha, MG / Brasil \\ Lívia de Oliveira Borges \\ liviadeoliveira@gmail.com \\ Universidade Federal de Alfenas - Varginha, MG / Brasil \\ Arne Vikan \\ arne.vikan@svt.ntnu.no \\ Universidade Norueguesa de Ciência e Tecnologia - Trondheim, Noruega
}

\begin{abstract}
Recebido em 14/09/2010
Aprovado em 22/09/2011

Disponibilizado em 01/08/2012

Avaliado pelo sistema double blind review

Revista Eletrônica de Administração

Editor: Luís Felipe Nascimento

ISSN 1413-2311 (versão on-line)

Editada pela Escola de Administração da Universidade Federal do Rio Grande do Sul.

Periodicidade: Quadrimestral
\end{abstract}

Sistema requerido: Adobe Acrobat Reader.

\section{RESUMO}

O estudo foi delineado com vistas a identificar os resultados de socialização organizacional de servidores atuantes em duas universidades públicas, de diferentes países (Brasil e Noruega), e compará-los numa perspectiva de análise transcultural. As amostras foram constituídas de professores e funcionários técnico-administrativos de uma universidade brasileira $(\mathrm{N}=72)$ e de uma universidade norueguesa $(\mathrm{N}=63)$. Na obtenção dos dados foi utilizado o Inventário de Socialização Organizacional (ISO) e uma ficha sociodemográfica. Considerando que os respondentes são provenientes de diferentes culturas, os procedimentos de análise dos dados foram precedidos de testes para a verificação da ocorrência de diferentes estilos de resposta entre os mesmos. Para a identificação e comparação dos resultados de socialização organizacional foram estimadas as médias nos fatores do ISO, aplicados testes $t$ para a comparação das médias e realizados testes ANOVA para verificar a ocorrência de diferenças significativas nos níveis de socialização organizacional em função da nacionalidade e da ocupação. Com base nos achados obtidos, observou-se que os servidores noruegueses, de modo geral, relataram maior integração às pessoas do que os servidores brasileiros e estes, por sua vez, tenderam a resultados mais satisfatórios de integração à organização. Notou-se, ainda, um efeito interativo entre nacionalidade e ocupação nos resultados de socialização organizacional, de forma que uma homogeneidade nos níveis de socialização de servidores docentes e técnico-administrativos foi verificada somente na universidade norueguesa, sendo expressivas as diferenças nos níveis de socialização dos servidores, em ocupações distintas, 
na universidade brasileira. Além disso, os funcionários técnico-administrativos noruegueses tenderam a se mostrar mais socializados do que os brasileiros, ao passo que, entre estes últimos, os docentes demonstraram uma socialização mais satisfatória comparativamente aos noruegueses. Atentando para os diferentes contextos em que se inserem as duas universidades estudadas, reflexões acerca de possíveis influências das orientações culturais nos resultados foram tecidas.

Palavras-chave: Socialização Organizacional, Contexto Cultural, Universidades Públicas, Servidores Brasileiros, Servidores Noruegueses.

\title{
ORGANIZATIONAL SOCIALIZATION: A COMPARATIVE STUDY AMONG BRAZILIAN AND NORWEGIAN CIVIL SERVANTS
}

\begin{abstract}
The aim of the study was to analyze the organizational socialization outcomes among civil servants at two public universities, from different countries (Brazil and Norway), comparing the results obtained in a cross-cultural perspective. The samples were composed of professors and technical-administrative employees at a Brazilian university $(\mathrm{N}=72)$ and a Norwegian university $(\mathrm{N}=63)$. The data collection instruments used were the Organizational Socialization Inventory (OSI) and a sociodemographic form. Data analysis was preceded by a number of tests to verify possible distinct response styles among the respondents, as they came from different cultures. Descriptive analysis, $t$-tests and ANOVA were performed to identify and compare organizational socialization outcomes. The results showed that the Norwegian civil servants, in general, reported better integration to people compared to Brazilians, which tended to be more integrated to organization than Norwegians. It was also observed and interaction effect between nationality and occupation, so that only among Norwegians civil servants in distinct occupations the organizational socialization outcomes were homogeneous. At the Brazilian university, professors related to be more socialized than technicaladministrative employees. Furthermore, Norwegian technical-administrative employees tended to be more socialized than their Brazilian counterparts, while Brazilian professors showed better socialization outcomes comparatively to Norwegian professors. Given the different contexts in which the two universities operate, some considerations about cultural orientations and their possible influence in the findings were proposed.
\end{abstract}

Keywords: Organizational Socialization, Cultural Context, Public Universities, Brazilian Civil Servants, Norwegian Civil Servants.

\section{Introdução}

A socialização organizacional, que foca o processo de adaptação a um novo cargo e uma nova realidade organizacional, tem se tornado um campo profícuo de pesquisas (SAKS; ASHFORTH, 1997; GRIFFIN; COLELLA; GOPARAJU, 2000; BAUER et al., 2007). O interesse pelo tema justifica-se, dentre outras razões, pelas contribuições que podem advir de uma socialização bem sucedida para a minimização do desencontro de expectativas entre 
trabalhador e organização, a identificação dos critérios de desempenho em nível individual e organizacional e o conhecimento dos valores, normas, redes de recursos e políticas da organização (COOPER-THOMAS; ANDERSON, 2006).

Entretanto, embora os esforços direcionados ao debate das questões que envolvem os processos de socialização organizacional tenham recebido considerável atenção na literatura internacional, relativamente poucas incursões sobre o tema são verificadas nas publicações nacionais (FREITAS, 2002; 2010; SHINYASHIKI, 2002; BORGES; ALBUQUERQUE, 2004; OLIVEIRA et al., 2008; CARVALHO, 2009). Conforme salientam Borges e Albuquerque (2004), a socialização organizacional tem sido, de modo geral, examinada a partir de diferenciados enfoques, os quais consideram questões relativas aos programas, ao conteúdo e às táticas organizacionais e individuais empregadas.

Os estudos voltados ao conteúdo da socialização abordam um conjunto de aspectos relacionados ao trabalho, os quais são considerados essenciais ao aprendizado de um indivíduo para que possa se tornar um membro proficiente e se sentir confortável na organização (ASHFORTH; SLUSS; SAKS, 2007). Adotando esse enfoque, o presente estudo parte do entendimento de que as especificidades presentes em contextos culturais distintos podem influenciar as condições nas quais ocorrem os processos de socialização, de forma a privilegiar determinados aspectos do conteúdo em detrimento de outros.

Dessa forma, o estudo foi delineado com vistas a analisar o caso de servidores atuantes em duas universidades públicas, de diferentes países (Brasil e Noruega), objetivando identificar os resultados de socialização organizacional de tais servidores e compará-los numa perspectiva de análise transcultural. A opção pelo espaço da universidade pública pautou-se no cenário brasileiro de reestruturação e expansão de tais instituições, o qual envolve a reposição de pessoal acompanhada de uma crescente exigência de produção, o que torna o assunto especialmente relevante neste contexto.

No tocante à escolha por um desenho transcultural, considerou-se a sua conveniência, há algum tempo apontada por vários estudiosos (AYCAN; KANUNGO, 2001; BAUER; TAYLOR, 2001; MILLER-LOESSI; PARKER, 2006), especialmente, no que diz respeito ao tema da socialização organizacional. Como esta tende a ser muito influenciada pela cultura por envolver metas (fins desejáveis) e seleção ou avaliação de comportamentos e eventos (processos ou táticas), Bauer e Taylor (2001) defendem a relevância dos desenhos transculturais nestes estudos. 
Socialização organizacional: estudo comparativo entre servidores públicos brasileiros e 342 noruegueses

Além disso, outro ponto que vem sendo debatido é o de que grande parte das teorias propostas e dos testes empíricos tem sido conduzida dentro dos Estados Unidos da América (EUA), o que gera um questionamento quanto à aplicabilidade de tais achados em outros contextos (BAUER; TAYLOR, 2001). Quando não focalizam apenas o contexto cultural daquele país, a maioria das pesquisas busca comparar resultados de participantes provenientes dos EUA com os de participantes de outros contextos culturais (AYCAN; KANUNGO, 2001).

Nesse sentido, a proposta de identificar os resultados de socialização organizacional de servidores brasileiros e a escolha por compará-los àqueles obtidos pelos servidores noruegueses, foi estimulada pelos achados de Hofstede e Hofstede (2005) e de Inglehart e Wezel (2005), os quais apontam os países do norte da Europa como aqueles que apresentam significativas distinções culturais em relação ao Brasil. Desta forma, a inclusão de um grupo de respondentes noruegueses no desenho da pesquisa atende aos critérios de diferenciação cultural, favorecendo as condições de desenvolvimento da análise. Cumpre salientar, ainda, as importantes diferenças socioeconômicas existentes entre estes dois países, especialmente no que se refere à distribuição de renda ${ }^{1}$.

Assim, o presente artigo se encontra organizado de forma a apresentar inicialmente a descrição de alguns aspectos centrais que caracterizam o contexto cultural brasileiro e norueguês, seguida de um breve resgate da literatura acerca dos conteúdos da socialização organizacional. Na sequência são apontados os procedimentos metodológicos adotados, a análise e discussão dos resultados e as considerações a respeito das principais contribuições e limitações do estudo.

\section{2. $O$ contexto cultural}

A relevância da cultura nacional para as práticas de socialização adotadas em cada país têm sido apontadas por alguns estudiosos (TRIANDIS, 1994; SMITH; BOND; KÂĞITÇIBAŞI, 2006), à medida que estas influenciam as características psicológicas dos indivíduos e a construção dos valores organizacionais. Assim, embora as organizações também tenham diferentes culturas, aquelas que se encontram num mesmo país tendem a

\footnotetext{
1 Uma das medidas de desigualdade de renda disponíveis no relatório de desenvolvimento humano das Nações Unidas (2007/2008), o coeficiente de Gini, apontava a Noruega como o segundo país em melhor distribuição de renda e o Brasil como o $70^{\circ}$ (http://hdr.undp.org/en/media/hdr_20072008_en_indicator_tables.pdf).
} 
refletir internamente a cultura nacional compartilhada (SMITH; BOND; KÂĞITÇIBAŞI, 2006).

Uma questão levantada, entretanto, tem sido aquela que discute a adequação dessa estratégia, comumente adotada em estudos transculturais, de se considerar nação como um sinônimo de cultura. Ros e Gouveia (2006, p.208) entendem que tal solução "traz implícita uma homogeneidade dentro das culturas nacionais que nem sempre traduz adequadamente a realidade; o que pode distorcer os dados da pesquisa e limitar a compreensão dos modelos culturais". Ryan et al. (1999) também criticam o uso de nação como base para examinar diferenças culturais, entendendo que tal abordagem não atenta para as possíveis diferentes subculturas existentes, ou conforme Muzzio (2010), para a possibilidade de que nos países haja uma diversidade cultural regional, o que, no caso brasileiro, é particularmente relevante diante da reconhecida pluralidade cultural do país.

De fato, Triandis (1994) nos lembra que a maioria dos Estados modernos consiste de variadas culturas, a maioria das corporações não tem culturas únicas e muitas das ocupações guardam alguns aspectos de culturas distintas (como vocabulário especial, pressuposições estabelecidas, etc.).

Por outro lado, Smith, Bond e Kâğitçibaşi (2006) argumentam que não apenas é conveniente, mas também sensível, abordar nações como unidades de análise. Considerando que suas fronteiras e prerrogativas políticas foram sendo definidas historicamente e que possuem características ecológicas, históricas, políticas, educacionais, legais, regulatórias, sociais e econômicas distintas, as nações constituem sistemas culturais. Desta forma, prosseguem os autores, apesar das diferenças potenciais, os diversos grupos de uma nação produzem perfis similares, principalmente se comparados àqueles observados entre grupos oriundos de outras nações. Em outras palavras, a diversidade entre os grupos culturais de uma mesma nação tende a ser menor do que aquela observada entre as nações como um todo. Por esta razão, entendem que as culturas nacionais constituem-se no foco apropriado dos estudos transculturais.

Estes autores defendem, ainda, a noção de que as organizações, embora se diferenciem culturamente entre si, tendem a refletir internamente a cultura nacional compartihada. Nesse sentido, os resultados de um estudo sobre cultura organizacional, desenvolvido em 20 unidades de dez diferentes organizações na Holanda e na Dinamarca, por Hofstede et al. (1990), demonstrou que ao passo que as culturas nacionais diferem principalmente em termos de conjuntos de valores compartilhados, as culturas organizacionais se diferenciam mais em 
Socialização organizacional: estudo comparativo entre servidores públicos brasileiros e 344 noruegueses

termos de práticas compartilhadas. Dessa forma, os membros de diferentes organizações, dentro de um mesmo país, poderiam compartilhar valores, mas trabalhar em organizações que estariam adotando maneiras distintas de implementá-los na prática.

A referência aos países como expressão de diferentes culturas, não significa pressupor, entretanto, que todos os indivíduos de mesma nacionalidade tenham o mesmo perfil psicossociológico. Naturalmente, que dentro das fronteiras de cada um dos países, as influências combinadas do contexto social mais amplo e das relações interpessoais mais imediatas irão contribuir para a existência de diferentes perfis em nível individual.

Da mesma forma, não se pode negar a influência da cultura nacional, na qual o indivíduo se encontra inserido, sobre seu comportamento. Triandis (1989) afirma que a cultura exerce influência sobre o tipo de pessoa que se constrói socialmente, e que os níveis de análise individual e cultural apresentam frequentemente correlação elevada. Portanto, as informações referentes ao nível cultural podem ser consideradas como um elemento, dentre outros, que contribui para explicar os resultados obtidos no nível individual.

É nessa vertente que o presente estudo, embora tendo no nível individual o seu foco principal de análise, considera algumas informações relevantes que se referem à orientação cultural predominante no Brasil e na Noruega, sem a pretensão, entretanto, de generalizar caracterizações da realidade desses países. Tais informações têm sido levantadas por estudiosos que abordam algumas dimensões características da cultura de diferentes grupos, tendo sido testadas em um grande número de países. Dentre estes, serão aqui apresentados, os estudos de Hofstede e de Inglehart e colaboradores, os quais foram selecionados tendo em vista o fato de que disponibilizam dados e informações que permitem uma contextualização comparativa entre os países envolvidos no estudo.

Utilizando dados de pesquisa realizada com empregados de uma companhia multinacional em quarenta países, e posteriormente expandindo para mais de cinquenta países, Hofstede derivou quatro dimensões principais, nas quais os sistemas de valores dominantes em diferentes culturas poderiam ser ordenados: distância de poder, coletivismo versus individualismo, feminilidade versus masculinidade e evitação de incerteza (HOFSTEDE; HOFSTEDE, 2005).

A dimensão de distância de poder reflete em que medida os membros menos poderosos de certos grupos sociais aceitam desigualdades de poder. Nas situações de trabalho em sociedades em que a distância de poder é elevada, os superiores e subordinados tendem a se considerarem mutuamente desiguais. Os sistemas salariais também tendem a retratar essa 
desigualdade, apresentando diferenças expressivas entre a remuneração do pessoal da base e do topo da organização (HOFSTEDE; HOFSTEDE, 2005). Os dados levantados para essa dimensão caracterizam a sociedade brasileira com uma elevada distância de poder, ao passo que na Noruega, as relações são mais equitativas.

No que se refere ao individualismo versus coletivismo, o primeiro é característico das sociedades em que cada pessoa assume maior responsabilidade por si mesmo e pela própria família, do que pelo grupo coletivo mais amplo (HOFSTEDE; HOFSTEDE, 2005). Uma vez que o individualismo e o coletivismo são considerados como polos opostos de uma mesma dimensão, a obtenção de baixos escores em individualismo seria indicativa de elevada tendência ao coletivismo. Gouveia et al. (2003) comentam, todavia, que tal polaridade tende a ser uma exceção, de forma que uma cultura deveria ser classificada pela predominância de um desses aspectos nas diferentes situações. Kâğitçibaşi (1994) também defende a noção de que o individualismo e o coletivismo, como dimensões independentes, podem coexistir no mesmo grupo e variar de acordo com as situações.

O fato é que dentre as dimensões propostas por Hofstede esta foi a que inspirou o maior número de estudos e polêmicas. No caso dos países aqui enfocados, por exemplo, os dados Hofstede e Hofstede (2005) apontam a Noruega como um país que tende mais ao individualismo, ao contrário do Brasil, caracterizado como uma cultura coletivista. Biaggio, Vikan e Camino (2005), entretanto, ao utilizarem tais dimensões em estudo comparativo da orientação cultural, no nível individual, entre brasileiros e noruegueses, observaram que as amostras de ambos os países apresentaram escores mais altos para a dimensão do coletivismo. Triandis (1995) também já havia observado que na Noruega o coletivismo regula, em muitos aspectos, o comportamento social e que embora a independência seja uma característica individualista presente, há um número substancial de elementos coletivistas.

Seguindo a mesma lógica apontada para o individualismo versus coletivismo, a dimensão que aborda a masculinidade versus feminilidade também foi estruturada em termos de polos opostos e apresenta indicadores apenas para o nível de masculinidade de uma cultura. Os escores avaliam em que medida os valores predominantes em uma sociedade são a assertividade e a competitividade. Para o Brasil, os indicadores foram de certo equilíbrio entre valores de masculinidade e feminilidade e para a Noruega, foi identificada uma predominância quase absoluta de orientação cultural mais feminina (HOFSTEDE; HOFSTEDE, 2005). Dentre os países analisados por Hofstede, aqueles com uma tradição católica tendiam a manter valores mais masculinos e aqueles com tradição protestante, valores 
Socialização organizacional: estudo comparativo entre servidores públicos brasileiros e 346 noruegueses

mais femininos. Embora o Brasil não chegue a figurar como uma sociedade em que predominam valores masculinos, comparativamente à Noruega, estes são mais presentes entre os brasileiros, o que pode estar relacionado à influência do catolicismo no Brasil.

Em referência à dimensão de evitação de incerteza, definida como o nível de tolerância das pessoas em relação a situações incertas e ambíguas, que se expressa numa maior ou menor necessidade de previsão e regras claras, o Brasil apresentou uma pontuação mais elevada do que a Noruega (HOFSTEDE; HOFSTEDE, 2005). Em sociedades caracterizadas por baixa evitação de incerteza os níveis de ansiedade tendem a ser baixos e a demonstração de emoções e agressão não são encorajadas. Em contrapartida, sociedades com alta evitação de incerteza tendem a elevados níveis de ansiedade e a uma demonstração emocional exacerbada, favorecendo uma sensação de estresse e urgência.

Comentando a validade do modelo das dimensões culturais que Hofstede propôs, Smith, Bond e Kâğitçibaşi (2006) acreditam que não obstante os cuidados metodológicos observados na condução da pesquisa, o fato dos itens dos questionários terem sido selecionados para outros propósitos (mensurar valores relacionados ao trabalho) pode ter ocasionado a omissão de importantes aspectos de diferença cultural. A despeito de tais limitações, todavia, as dimensões identificadas em seu estudo têm sido amplamente utilizadas no desenvolvimento de pesquisas transculturais (MILLER-LOESSI; PARKER, 2006).

Isso é particularmente verdadeiro no caso do Brasil, pois, como salientam Alcadipani e Crubelate (2003), os estudos desenvolvidos aqui sobre cultura organizacional têm sido fortemente influenciados pela pesquisa de Hofstede. Estes autores externam sua preocupação a esse respeito, tendo em vista que tais estudos tendem a aceitar, sem problematização, os pressupostos de Hofstede, ignorando ou não discutindo o fato de que estes constituem uma forma de generalização que não contempla a pluralidade ampla e diversa da cultura brasileira. Alertam, nesse sentido, que embora não considerem tal modelo inválido, a homogeneização nele proposta deve ser problematizada, para evitar uma simplificação das interpretações.

Outro autor cujos estudos tomaram como base uma série de dados provenientes de levantamentos realizados em vários países foi Inglehart. Por meio do projeto World Values Survey estes dados vêm sendo coletados desde o ano de 1981 e até o ano de 2007 já haviam sido realizadas cinco fases de levantamentos de informações, envolvendo, ao final, 88 países que compreendem quase $90 \%$ da população mundial (INGLEHART et al., 2008).

A análise destes dados permitiu observar uma diferença sistemática nas normas políticas e sociais e nas crenças religiosas predominantes em sociedades de alta e baixa renda. 
Com o intuito de identificar os principais elementos desta variação cultural global, Inglehart e Baker (2000) realizaram análises fatoriais, das quais emergiram duas dimensões que refletiam uma polarização entre: 1) uma orientação secular e racional versus tradicional; e, 2) valores de sobrevivência versus autoexpressão. A orientação tradicional é caracterizada por uma forte ênfase na religião e no respeito pela autoridade, e também por níveis elevados de conformidade social e de orgulho nacional. As sociedades predominantemente agrárias tendem a enfatizar valores tradicionais e as sociedades mais industrializadas tendem a enfatizar a orientação secular e racional.

Por sua vez, a dimensão de sobrevivência versus autoexpressão aborda os aspectos de confiança interpessoal, tolerância, bem-estar subjetivo, apoio à igualdade de gênero, ativismo político e autoexpressão, que tendem a emergir de forma mais intensa em sociedades pósindustriais, que desfrutam de elevados níveis de segurança física e econômica. Um componente central desta dimensão é a polarização entre valores materialistas e pósmaterialistas (INGLEHART; BAKER, 2000).

Informações relativas ao Brasil nestas dimensões mostram a tendência a uma orientação mais tradicional, que se manteve praticamente inalterada durante o período entre 1990 a 2006. Uma leve predominância de valores de sobrevivência foi também constatada entre os brasileiros durante a primeira coleta realizada no país, no ano de 1990. Tal situação, todavia, se reverteu nos anos seguintes, de forma que em 2006 passou a se constatar uma predominância dos valores de autoexpressão (INGLEHART; WEZEL, 2005).

Com relação à Noruega, constatou-se que houve uma tendência crescente, entre os anos de 1981 a 1995, tanto à orientação secular e racional quanto à predominância de valores de autoexpressão (INGLEHART; WEZEL, 2005). Cumpre salientar que os dados do ano de 1995 mostram que a manifestação de valores de autoexpressão naquela sociedade foi significativamente mais intensa do que no Brasil. Uma vez que o levantamento realizado em 2006 não envolveu respondentes da Noruega, não foi possível observar se a magnitude desta diferenciação se manteve entre os anos de 1995 e 2006.

No que se refere ao posicionamento das sociedades neste espaço bidimensional, os autores defendem que este reflete não apenas o seu nível de desenvolvimento econômico, mas também sua estrutura ocupacional e religião, dentre outras influências históricas. Inglehart e Baker (2000), por exemplo, observaram que a maioria das sociedades historicamente protestantes apresentava maiores níveis de confiança interpessoal do que as sociedades historicamente católicas, mesmo depois de controlar os níveis de desenvolvimento 
Socialização organizacional: estudo comparativo entre servidores públicos brasileiros e 348 noruegueses

econômico. De fato, no caso do Brasil e da Noruega é possível constatar diferenças tanto em termos de desenvolvimento econômico, quanto de tradição religiosa entre esses dois países. $\mathrm{Na}$ Noruega, com histórico de influência protestante e maior nível de desenvolvimento econômico, os valores de autoexpressão emergiram de forma mais intensa do que no Brasil.

Essa compreensão, ainda que breve acerca dos contextos culturais em que se inserem as duas universidades aqui estudadas, é de grande relevância, tendo em vista que os fenômenos têm sentidos e/ou significados de acordo com o contexto em que se desenvolvem. Por essa razão, tais informações podem facilitar as discussões acerca dos resultados de socialização organizacional observados.

\section{Os conteúdos e a aprendizagem no processo de socialização organizacional}

O processo de adaptação do indivíduo a uma nova realidade organizacional ou a um novo posto de trabalho constitui um evento gerador de estresse, à medida que tais transições são normalmente acompanhadas de elevadas expectativas e sentimentos de incerteza (VAN MAANEN; SCHEIN, 1979; FELDMAN; BRETT, 1983; NELSON, 1987; SAKS, 1994), as quais podem resultar em conseqüências indesejáveis para os indivíduos e para as organizações. O aumento dos custos da rotatividade de pessoal, por exemplo, tende a ser mais elevado entre os iniciantes (ALLEN, 2006), o que se torna problemático à medida que se considera o investimento significativo que é feito nos processos de recrutamento, seleção e treinamento (ASHFORTH; SLUSS; SAKS, 2007).

Por esta razão, a importância de um processo de socialização organizacional bem sucedido tem sido discutida entre os estudiosos do tema, os quais apontam que o sucesso na socialização organizacional pode ser observado a partir de indicadores de resultados proximais e distais. O ajustamento, por exemplo, é considerado por Ashforth, Sluss e Saks (2007) como um resultado distal, pois o mesmo é promovido a partir de resultados proximais, como a aquisição de conhecimento sobre o contexto de trabalho. Dentre os resultados distais, os mais citados na literatura são: a satisfação no trabalho e o comprometimento organizacional, a redução da ansiedade, do estresse e da intenção de deixar o emprego. Com relação aos resultados proximais, estes incluem vários tipos de conhecimento (relacionados aos conteúdos da socialização), domínio da tarefa, clareza de papel, congruência de valores, integração social e desempenho, dentre outros (SAKS; ASHFORTH, 1997; COOPERTHOMAS; ANDERSON, 2006).

Os primeiros trabalhos que abordaram o tema da socialização organizacional focaram o processo, primordialmente, a partir do ponto de vista das organizações, gerando duas 
perspectivas de estudos: aquela que aborda as táticas organizacionais empregadas (VAN MAANEN; SCHEIN, 1979; JONES, 1986) e a que foca os estágios pelos quais os iniciantes passam durante o processo de socialização (LOUIS,1980; FELDMAN, 1981; NELSON, 1987).

Ainda na década de 1980, alguns pesquisadores (JONES, 1983; REICHERS, 1987; dentre outros) argumentavam que a literatura de socialização deveria adotar uma perspectiva interacionista simbólica, que não considerasse apenas as variáveis situacionais, mas também as individuais; o que colaborou para incitar um novo direcionamento das pesquisas, principalmente nos anos de 1990 (OSTROFF; KOZLOWSKI, 1992; MORRISON, 1993a; 1993b, SAKS, 1994; 1995; ADKINS, 1995; ASHFORD; BLACK, 1996; MAJOR; KOZLOWSKI, 1997), voltado para a preocupação com os efeitos diretos de diferenças individuais no processo de socialização e para a maneira pela qual os iniciantes se comportavam pró-ativamente para facilitar este processo (WANBERG; KAMMEYERMUELLER, 2000; FINKELSTEIN, KULAS; DAGES, 2003; CARR et al., 2006).

Outro enfoque de pesquisa que passou a ser adotado por muitos estudiosos, o qual é também utilizado no presente estudo, foi aquele relacionado à aprendizagem e ao conteúdo da socialização. O estudo da socialização organizacional como um processo de aprendizagem tem como foco o que realmente se aprende e internaliza (CHAO et al., 1994, OSTROFF; KOZLOWSKI, 1992), ou seja, o conteúdo da socialização, reconhecendo-se o papel ativo dos sujeitos em tal processo (LISBONA; MORALES; PALACÍ, 2009). Cooper-Thomas e Anderson (2006, p. 497) afirmam que desde a década de 1990 tem havido um consenso entre os estudiosos da área de que "o aprendizado é a essência da socialização organizacional, pois revela a extensão na qual o iniciante se encontra socializado".

O exame deste aprendizado (e, por consequência, dos resultados de socialização organizacional) compreende, por sua vez, uma definição de quais aspectos do trabalho devem ser analisados na abordagem de conteúdo da socialização. Num esforço de identificação destas dimensões de conteúdo, várias tipologias têm sido propostas na literatura, algumas das quais incluíram também escalas para mensurar a aquisição de conteúdo.

Ostroff e Kozlowski (1992), por exemplo, apresentaram uma medida de socialização organizacional envolvendo quatro domínios de conteúdo: tarefas do emprego, papéis de trabalho, processos de grupo e atributos organizacionais. O domínio das tarefas envolve fatores como deveres e obrigações, responsabilidades, prioridades, modo de usar equipamentos e de lidar com questões de rotina. Os papéis de trabalho focam os limites da 
Socialização organizacional: estudo comparativo entre servidores públicos brasileiros e 350 noruegueses

autoridade e da responsabilidade, as expectativas e os comportamentos adequados ao posto. Os processos de grupo referem-se à interação com os colegas, às normas e valores do grupo e à estrutura normativa do grupo de trabalho e os atributos organizacionais dizem respeito às políticas, ao poder, ao conjunto de valores do sistema organizacional, à missão e ao estilo de liderança.

Outra tipologia proposta, e que tem sido uma das mais reconhecidas e comentadas na literatura é a de Chao et al. (1994). A escala proposta por estes autores é também a que tem sido utilizada com mais frequência por outros estudiosos, ainda que raramente em sua forma integral, pois normalmente os pesquisadores utilizam somente algumas de suas dimensões. Tal tipologia defende a existência de seis domínios de conteúdo da socialização organizacional, os quais abrangem:

(1) Proficiência de desempenho - avalia a extensão na qual os indivíduos dominam suas tarefas;

(2) Pessoas - envolve a satisfação nas relações com membros da organização;

(3) Políticas - abrange o sucesso de um indivíduo em obter informações com respeito às relações de trabalho formais e informais e às estruturas de poder dentro da organização;

(4) História - diz respeito ao conhecimento das tradições, costumes, mitos e rituais que compõem a cultura da organização;

(5) Linguagem - aborda o conhecimento do indivíduo sobre a linguagem técnica profissional, bem como a familiaridade com a linguagem informal da organização;

(6) Objetivos e valores organizacionais - compreende a interiorização das regras ou princípios que mantêm a integridade da organização.

Por meio do estudo empírico longitudinal em que identificaram essas dimensões da socialização organizacional, Chao et al. (1994) observaram, também, que geralmente as pessoas bem socializadas em seus papéis organizacionais têm maiores rendimentos pessoais, são mais satisfeitas, mais envolvidas com suas carreiras, mais adaptáveis e têm um melhor senso de identidade pessoal do que as pessoas que são menos socializadas.

Outro estudo, desenvolvido por Morrison (1995) integrou várias tipologias para derivar sete domínios de conteúdo. Como será possível observar, os domínios apresentados neste estudo também têm muitas similaridades com as seis dimensões propostas por Chao et al. (1994). São eles: informação técnica sobre como executar as tarefas; informação de atribuições sobre as requisições e expectativas do papel de trabalho; informação social sobre 
outras pessoas e os relacionamentos com as mesmas; informação avaliativa sobre como o desempenho e o comportamento estão sendo apreciados por outros na organização; informação normativa sobre a cultura organizacional; informação organizacional sobre a estrutura, procedimentos, produtos/serviços e resultados da empresa; e informação política sobre a distribuição de poder dentro da organização.

Ainda, partindo do pressuposto que a maioria das variáveis pesquisadas em socialização organizacional pode ser classificada e/ou agrupada em poucas categorias, Taormina (1997) apresentou um modelo de socialização organizacional como um processo contínuo, que envolve quatro domínios: (1) treinamento, (2) entendimento, (3) suporte proporcionado por colegas de trabalho, (4) perspectivas de futuro. No que diz respeito à sua estrutura, cada domínio foi concebido por Taormina (1997) como uma esfera conceitual, na qual se encontram as dimensões previamente pesquisadas por estudiosos em socialização organizacional, como por exemplo, as dimensões examinadas por Chao et al. (1994), cada uma delas se encaixando num ou noutro dos quatro domínios.

Haueter, Macan e Winter (2003) também construíram uma escala compreendendo três dimensões (organização, grupo, e tarefa) e que foi denominada Questionário de Socialização de Iniciantes (Newcomer Socialization Questionnaire - NSQ). Cada uma destas três dimensões se refere a um nível distinto de socialização. Na construção da escala, os itens foram organizados de forma a avaliar a aquisição de conhecimento sobre cada dimensão e também sobre os comportamentos apropriados no que se refere a cada uma delas.

Examinando-se cuidadosamente as tipologias aqui apresentadas, constata-se, portanto, que todas trazem a noção comum de que a aquisição de conhecimento abrange o cargo e o papel, as relações interpessoais e grupais, e a natureza da organização como um todo. Mais especificamente, nos trabalhos de Ostroff \& Kozlowski (1992) e Haueter, Macan e Winter (2003), tal divisão na abordagem do conteúdo aparece de forma bastante clara.

Alguns autores (BAUER et al., 2007; COOPER-THOMAS; ANDERSON, 2006), todavia, consideram que, embora todos os instrumentos de mensuração se mostrem muito promissores, precisam ainda ser melhor desenvolvidos e revalidados para melhor diferenciar os domínios, testar hipóteses de aprendizagem paralela em diferentes níveis (por exemplo, grupo e organização), testar amplitude de conteúdo e responder às questões relativas a possíveis omissões de domínios.

Nessa vertente, Borges et al. (2010) desenvolveram uma escala de mensuração, tomando como base as dimensões de socialização e o questionário propostos por Chao et al. 
Socialização organizacional: estudo comparativo entre servidores públicos brasileiros e 352 noruegueses

(1994). Após a criação e reconstrução de vários itens, com base em entrevistas com servidores docentes e técnico-administrativos de duas instituições públicas, sendo uma delas uma universidade federal e na revisão da literatura especializada, a versão resultante foi denominada de Inventário de Socialização Organizacional (ISO), o qual é composto pelos seguintes fatores:

- Acesso às Informações (políticas) - diz respeito ao conhecimento de datas importantes, processos organizacionais, critérios e poder;

- Competência e Pró-atividade - refere-se à capacidade de criar, ser eficaz, produtivo, ativo e de buscar informação;

- Integração às Pessoas - envolve o sentimento de ser aceito pelos outros, incluído na equipe, na organização e participar nos processos de tomada de decisão;

- Não Integração à Organização - inclui a ausência do domínio da linguagem, do emprego, do conhecimento acerca dos processos organizacionais e da cultura organizacional;

- Qualificação Profissional - aborda o conhecimento e a experiência profissional, o domínio da linguagem profissional e das tarefas;

- Objetivos e Valores Organizacionais - compreende o conhecimento e a identificação com os objetivos e prioridades organizacionais e, ainda, o conhecimento da história organizacional;

- Linguagem e Tradição - abrange o domínio da linguagem profissional e organizacional, o conhecimento das tradições e da história dos colegas, bem como saber identificar as pessoas mais influentes (BORGES et al., 2010).

Estes fatores constituem a tipologia de conteúdo a ser adotada neste estudo, a qual irá fornecer os indicadores para analisar os resultados de socialização organizacional.

\section{Estratégias metodológicas}

\subsection{População e amostra}

$\mathrm{Na}$ constituição do universo populacional encontram-se os servidores (professores e funcionários técnico-administrativos) de uma universidade pública brasileira, admitidos na instituição entre os anos de 2002 a 2005 e de uma universidade pública norueguesa, admitidos no período de 2003 a 2006. A seleção destas instituições foi realizada em conformidade com as recomendações de Aycan e Kanungo (2001), no sentido de se equiparar os grupos a serem 
estudados comparativamente por setor, indústria, tipo de produção, tecnologia e características da força de trabalho.

As amostras destas duas instituições constituíram-se, respectivamente de 72 e 63 sujeitos. O critério adotado na constituição das mesmas foi o de acessibilidade dos participantes, constituindo o que é denominado de amostra acidental. Cumpre esclarecer a diferença entre amostra acidental (não probabilística) e aleatória (probabilística): para esta última, é requerido que cada elemento tenha probabilidades conhecidas e positivas de serem escolhidos para compor a amostra; enquanto que, na amostra acidental, por sua vez, o critério de inclusão é a acessibilidade dos sujeitos, ou o fato de estarem em um determinado lugar, em determinada hora (KISH, 1996; SARRIÁ; GUARDIÃ; FREIXA, 1999; SCARPARO, 2000).

Com base nas características descritas na Tabela 1, é possível afirmar que se obteve um nível satisfatório de equivalência entre as duas amostras. Os servidores de ambas as universidades se encontram distribuídos em proporções aproximadas no que diz respeito à ocupação, idade, gênero e tempo de serviço na instituição.

Tabela 1 - Perfil sociodemográfico dos servidores brasileiros e noruegueses

\begin{tabular}{lcc}
\hline Perfil dos Servidores & Universidade Brasileira & Universidade Norueguesa \\
\hline $\begin{array}{l}\text { Ocupação } \\
\text { Servidores docentes }\end{array}$ & $33(45,8 \%)$ & $30(47,6 \%)$ \\
Servidores técnico-administrativos & $39(54,2 \%)$ & $33(52,4 \%)$ \\
& Menos de 30 anos $=12,5 \%$ & Menos de 30 anos $=4,8 \%$ \\
Faixa etária & 30 a 40 anos $=43,1 \%$ & 30 a 40 anos $=50,8 \%$ \\
& 41 a 50 anos $=37,5 \%$ & 41 a 50 anos $=25,4 \%$ \\
& 51 a 60 anos $=5,6 \%$ & 51 a 60 anos $=17,5 \%$ \\
Gênero & Mais de 61 anos $=1,4 \%$ & Mais de 61 anos $=1,6 \%$ \\
Feminino & $44(61,1 \%)$ & $33(52,4 \%)$ \\
Masculino & $28(38,9 \%)$ & $30(47,6 \%)$ \\
& De 24 a 69 meses & De 18 a 70 meses \\
Tempo de serviço na universidade & Média $=52,9$ meses & Média $=44,6$ meses \\
& $($ D.P. $=10,8)$ & $($ D.P. $=13,6)$
\end{tabular}

Nota: D.P. = Desvio Padrão

Fonte: autores

\subsection{Instrumentos de pesquisa}

Para a obtenção dos dados referentes à socialização organizacional dos servidores foi utilizado o Inventário de Socialização Organizacional (ISO) (BORGES et al., 2010), que conta com 45 itens, aos quais os participantes respondem segundo uma escala variando gradualmente entre -2 (forte discordância) e 2 (forte concordância), passando por -1 
Socialização organizacional: estudo comparativo entre servidores públicos brasileiros e 354 noruegueses

(discordância), 0 (neutro) e 1 (concordância). Após o processo de adaptação e validação, o ISO mostrou-se capaz de mensurar sete fatores, cujos alfas de Cronbach variam de 0,70 a 0,83. Estes fatores são: Acesso às Informações, Competência e Pró-atividade, Integração às Pessoas, Não Integração à Organização, Qualificação Profissional, Objetivos e Valores Organizacionais e Linguagem e Tradição. O fator de Não Integração à Organização foi invertido e estará sendo aqui discutido em termos de Integração à Organização.

Para a aplicação entre os servidores da universidade norueguesa, o ISO foi traduzido, com o auxílio de pesquisadores multilíngues, para o norueguês. Tal procedimento se encontra em conformidade com a recomendação de Ros e Gouveia (2006), que apontam como mais adequado nesses casos: a tradução de uma língua para outra, seguida da tradução reversa (backtranslation) ou a consulta a um grupo de especialistas nos idiomas necessários ao estudo (opção aqui adotada). A este respeito, Bauer e Taylor (2001) assinalam que a reunião de pesquisadores das diferentes nações/culturas envolvidas, para participar conjuntamente em cada um dos aspectos do desenvolvimento do estudo, é uma alternativa que pode ser efetiva para lidar com todas as exigências metodológicas de uma pesquisa transcultural. De fato, o referido grupo, com pesquisadores de ambas as culturas, participou, conjuntamente, em boa parte das etapas de planejamento e desenvolvimento do presente estudo.

A identificação do perfil dos respondentes foi realizada por meio da utilização de uma ficha sociodemográfica, estruturada para coletar informações relativas à faixa etária, gênero, nível de instrução, ocupação, tempo de serviço na instituição e renda familiar.

\subsection{Coleta de dados}

Os procedimentos de coleta das informações necessárias à realização do estudo foram divididos em duas fases. A primeira delas foi realizada junto a um total de 153 servidores da universidade brasileira. Todos os participantes da pesquisa receberam um protocolo contendo o inventário de socialização organizacional e uma ficha sociodemográfica, além de informações sobre os objetivos da pesquisa e instruções gerais para o preenchimento dos questionários.

O início das atividades ocorreu por meio de visitas aos locais de trabalho dos servidores técnico-administrativos. Os procedimentos de devolução dos questionários variaram em função da disponibilidade de tempo dos pesquisados; de forma que, em alguns casos, estes foram respondidos prontamente e, em outros, foi marcada uma data para a devolução dos mesmos. Aos professores, os questionários foram enviados por meio de malote 
institucional, acompanhados de uma carta expondo os objetivos do estudo e solicitando a colaboração dos mesmos.

Para a segunda fase da coleta, realizada junto aos servidores da universidade norueguesa (154 indivíduos) estabeleceu-se um contato inicial com todos os departamentos distribuídos no campus para o levantamento de informações e escolha do procedimento mais adequado para a aplicação dos questionários. Definiu-se pela mesma estratégia adotada com os professores da universidade brasileira, qual seja o envio de questionários aos servidores por meio de malote institucional.

Ao final da coleta foi contabilizada a devolução de 72 questionários válidos respondidos por parte dos servidores brasileiros e de 63 pelos servidores noruegueses (taxas de retorno da ordem de $47 \%$ e $40 \%$, respectivamente).

\subsection{Tratamento dos dados}

Considerando as observações de vários autores (BACHMAN; O’MALLEY, 1984; HUI; TRIANDIS, 1989; HERK; POORTINGA; VERHALLEN, 2004; SMITH; BOND; KÂĞITÇIBAŞI, 2006) que têm aludido à possibilidade de diferenças sistemáticas nos estilos de resposta entre países ou grupos culturais, atentou-se para a importância da realização de checagens prévias no processo de análise dos dados. Segundo estes autores, se um respondente apresenta viés consistentemente entre itens e métodos, configurando o denominado estilo de resposta, isto pode prejudicar a equivalência estrutural, dificultando a comparabilidade dos escores obtidos por diferentes grupos culturais.

Existem três tipos de viés de resposta que são considerados os mais problemáticos na aplicação de questionários:

- Desejabilidade social - tendência a se fazer parecer bom em termos das normas culturais prevalecentes, quando se responde a um entrevistador sobre os itens de um questionário;

- Aquiescência - tendência a concordar mais do que discordar com os itens, independente do conteúdo; e,

- Respostas extremas - tendência a usar as extremidades das escalas de resposta, a despeito do conteúdo (HERK; POORTINGA; VERHALLEN, 2004).

Existem também procedimentos que podem ser utilizados para detectar a presença destes estilos de resposta entre os participantes da pesquisa, além daqueles de padronização para minimizar os vieses. Assim, o primeiro passo no tratamento dos dados foi a realização de 
Socialização organizacional: estudo comparativo entre servidores públicos brasileiros e 356 noruegueses

checagens a respeito de possíveis diferenças sistemáticas nos estilos de resposta entre os servidores das universidades brasileira e norueguesa, cujos resultados de socialização foram, posteriormente, comparados.

As tendências de resposta individual destes servidores foram quantificadas de acordo com os procedimentos descritos por Bachman e O’Malley (1984), com vistas à obtenção de indicadores que permitissem identificar a ocorrência de aquiescência ou de respostas extremas. Considerando-se que os questionários não foram respondidos ao entrevistador, mas entregues aos participantes para preenchimento, descarta-se a possibilidade de ocorrência do viés de desejabilidade social.

Dois indicadores iniciais foram computados para cada respondente (exceto para aqueles em que havia missing) no intuito de gerar os indicadores médios de aquiescência e de respostas extremas. Os indicadores iniciais, denominados de Viés de Concordância e Viés de Discordância, foram calculados por meio da contagem de respostas nas categorias 5 e 1 na escala de socialização. O número obtido foi dividido pelo total de itens, de modo que o resultado para ambos os indicadores foi uma média que variou entre 0,00 e 1,00.

Somando-se as médias dos indicadores de concordância e de discordância resultaram os indicadores de respostas extremas, cujos valores também oscilaram entre 0,00 e 1,00. E, finalmente, a diferença entre os indicadores de concordância e de discordância foi computada, resultando no indicador de aquiescência (variando de $-1,00$ a 1,00).

A obtenção de tais indicadores, apresentados na Tabela 2, permite comparar os estilos de resposta entre dois ou mais grupos provenientes de diferentes culturas. A ocorrência de vieses de respostas extremas ou de aquiescência é confirmada quando se identifica uma tendência de certos grupos em obter valores significativamente mais elevados nos indicadores computados.

Tabela 2 - Média e desvio padrão dos indicadores de estilo de resposta

\begin{tabular}{lccc}
\hline Servidores & $\boldsymbol{N}$ & $\begin{array}{c}\text { Respostas extremas } \\
\text { Média } \\
(D . P .)\end{array}$ & $\begin{array}{c}\text { Aquiescência } \\
\text { Média } \\
(D . P .)\end{array}$ \\
\hline Universidade brasileira & 67 & $\begin{array}{c}0,478 \\
(0,265)\end{array}$ & 0,252 \\
Universidade norueguesa & 61 & $\begin{array}{c}0,429 \\
(0,239)\end{array}$ & $0,224)$ \\
& & & $(0,186)$ \\
\hline
\end{tabular}

Nota: D.P. = Desvio padrão

Fonte: autores 
Com vistas à comparação das médias obtidas para os indicadores de respostas extremas e aquiescência entre os dois grupos, procedeu-se à aplicação do teste $t$. Não foi constatada diferença significativa para nenhum dos dois indicadores, o que denota a existência de equivalência estrutural, viabilizando a comparabilidade dos resultados de socialização organizacional entre as duas amostras. Identifica-se aqui uma oportunidade para futuras pesquisas que, através da utilização de outros tipos de questionários entre respondentes desses países, possam constatar se tal equivalência tende a se manter entre as amostras analisadas.

Após a realização de tais testes, partiu-se para a identificação dos resultados de socialização organizacional dos participantes do estudo, tendo sido estimadas as médias (e desvio padrão) dos pontos atribuídos aos itens dos questionários, de forma a obter os escores das duas amostras em cada um dos fatores referentes a este construto. Foram aplicados testes $t$ para a comparação das médias obtidas pelas duas amostras (brasileiros e noruegueses).

Considerando-se, ainda, o fato de que os servidores participantes da pesquisa se encontram divididos em duas categorias ocupacionais, definiu-se por verificar a ocorrência de diferenças significativas nos resultados de socialização organizacional, não somente em função da nacionalidade, mas também da ocupação, por meio da realização de testes ANOVA.

\section{Resultados e discussão}

Com base nos resultados de socialização organizacional dos servidores das universidades brasileira e norueguesa (Tabela 3), é possível afirmar, de modo geral, que estes tendem a uma percepção de que estão sendo bem sucedidos nesse processo. Para alguns fatores, como os de Qualificação Profissional, Competência e Pró-atividade e Integração à Organização, os escores médios são superiores a 4,00, nas duas instituições, indicando um maior êxito nestes aspectos da socialização. Deve-se lembrar que o escore 4 significa, na escala do ISO, concordância. Quando os escores estão acima de 4, são indicativos de que os pontos atribuídos aos itens que representam o fator tendem a ter variado entre 4 (concordância) e 5 (forte concordância). Além disso, como o desvio padrão foi relativamente pequeno nesses fatores, principalmente no de Competência e Pró-atividade, tem-se uma baixa dispersão em torno das médias. 
Socialização organizacional: estudo comparativo entre servidores públicos brasileiros e 358 noruegueses

Tabela 3 - A socialização organizacional dos servidores brasileiros e noruegueses

\begin{tabular}{lcccc}
\hline Fatores do ISSO & Média & $\begin{array}{c}\text { D.P. } \\
\text { Univ.B }\end{array}$ & $\begin{array}{c}\text { Média } \\
\text { Univ.. }\end{array}$ & $\begin{array}{c}\text { D.P. } \\
\text { Univ.N }\end{array}$ \\
\hline Acesso às Informações & 3,68 & 0,82 & 3,86 & 0,64 \\
Competência e Pró-atividade & 4,36 & 0,46 & 4,33 & 0,40 \\
Integração às Pessoas & 3,96 & 0,93 & 4,31 & 0,53 \\
Integração à Organização & 4,36 & 0,59 & 4,13 & 0,57 \\
Qualificação Profissional & 4,49 & 0,58 & 4,48 & 0,41 \\
Objetivos e Valores Organizacionais & 3,84 & 0,75 & 3,96 & 0,56 \\
Linguagem e Tradição & 3,81 & 0,67 & 3,98 & 0,51 \\
\hline
\end{tabular}

Nota: Univ.B = Universidade brasileira / Univ.N = Universidade Norueguesa / D.P.= Desvio padrão

Fonte: autores

O fator de Integração às Pessoas também obteve, em geral, escores que indicam uma autopercepção que tende a variar entre concordância e forte concordância, exceto no caso dos servidores brasileiros, que apresentaram média de 3,96, o que denota uma aproximação do nível de concordância, com atribuições neutras em alguns itens do fator. Além disso, o desvio padrão em tal fator, na universidade brasileira, foi o mais elevado de todos (D.P.= 0,93), o que indica a existência de alguns servidores naquela instituição com dificuldades de se integrar socialmente, no que diz respeito ao sentimento de ser aceito pelos outros, incluído na equipe e participativo nos processos de tomada de decisão.

Caso similar ocorre com o fator de Acesso às Informações que também apresentou desvio padrão relativamente elevado, em ambas as instituições, além de uma tendência a médias mais baixas, o que denota uma dificuldade mais generalizada no que se refere ao conhecimento das políticas e processos organizacionais, podendo impactar negativamente o desempenho individual.

Quanto aos fatores de Objetivos e Valores Organizacionais e de Linguagem e Tradição, os escores médios estão entre o ponto neutro e a concordância e embora estes pareçam ligeiramente mais elevados para os servidores da universidade norueguesa, a realização do teste $t$, comparando os resultados para os servidores de ambas as instituições, mostrou que não há diferenças significativas entre os mesmos. Somente entre as médias apresentadas nos fatores designados por Integração às Pessoas ( $\mathrm{t}=-2,69 ; \mathrm{p}<0,01)$ e Integração à Organização $(\mathrm{t}=-2,26 ; \mathrm{p}<0,05)$ os resultados do teste $t$ apontaram diferenças significativas. Tais achados indicam que na universidade norueguesa, os servidores tendem a se sentir mais integrados socialmente, quando comparados aos servidores brasileiros, e que estes últimos 
apresentaram uma tendência de se integraram melhor à organização, como um todo, do que os servidores noruegueses.

Refletindo sobre os resultados de maior Integração às Pessoas por parte dos servidores da universidade norueguesa, conquanto esta possa parecer contraditória, principalmente ao se considerar que Hofstede e Hofstede (2005) identificaram uma orientação mais individualista naquela cultura, cumpre resgatar algumas considerações anteriormente tecidas. A primeira delas diz respeito à afirmação de Triandis (1995) a respeito de uma existência de traços coletivistas na sociedade norueguesa e à verificação, em pesquisa anterior (BIAGGIO; VIKAN; CAMINO, 2005), de uma predominância, no nível individual, de valores coletivistas entre noruegueses, além da noção, defendida por Kâğitçibaşi (1994), de que o individualismo e o coletivismo, como dimensões independentes, podem coexistir no mesmo grupo e variar de acordo com as situações.

A segunda se refere ao maior nível de confiança interpessoal identificado na Noruega, em comparação ao Brasil. Inglehart e Baker (2000) já haviam observado que a maioria das sociedades historicamente protestantes apresenta níveis mais elevados de confiança interpessoal do que as sociedades historicamente católicas, mesmo depois de controlar os níveis de desenvolvimento econômico. Como a confiança interpessoal mais elevada, normalmente, leva as pessoas a assumirem que os outros se comportarão de maneira gentil quando abordados, isto pode estar atuando como um dos aspectos facilitadores de uma maior integração entre os iniciantes na universidade norueguesa. Outro fato que não pode ser, contudo, ignorado, diz respeito à organização do horário de trabalho naquela instituição ${ }^{2}$, o qual, por ser mais compacto, mantém os servidores presentes durante todo o expediente no espaço de trabalho, inclusive no momento da refeição, criando, assim, maiores oportunidades para sua integração.

No que se refere aos resultados de maior Integração à Organização por parte dos servidores da universidade brasileira, duas considerações acerca de possíveis influências da orientação cultural predominante no Brasil também são propostas. A primeira trata da tendência à evitação de incerteza mais elevada na sociedade brasileira do que na norueguesa e, a segunda, da orientação tradicional (em oposição à orientação secular e racional), presente no Brasil.

De acordo com Hofstede e Hofstede (2005), são elementos importantes no ambiente de trabalho em países com elevada evitação de incerteza: aversão à ambiguidade, necessidade

\footnotetext{
${ }^{2}$ Os servidores noruegueses realizam um turno de trabalho contínuo que se inicia as 8 horas da manhã e se estende até as 16 horas, com um pequeno intervalo para o lanche por volta das 12 horas.
}

REAd I Porto Alegre - Edição 72 - N 2 - maio/agosto 2012 - p. 339-371 
Socialização organizacional: estudo comparativo entre servidores públicos brasileiros e 360 noruegueses

de precisão e formalização nas organizações e maior confiabilidade em profissionais que detenham expertise na sua área de atuação. $\mathrm{O}$ fator de socialização denominado Integração à Organização, por sua vez, descreve o domínio da linguagem, do emprego, do conhecimento acerca dos processos organizacionais e da cultura organizacional; elementos que propiciam maior clareza e segurança à atuação profissional do servidor. Logo, seria razoável supor que a orientação cultural brasileira estaria exercendo alguma influência entre aqueles servidores, no sentido de buscar uma melhor integração à organização, como forma de evitar a incerteza.

Além disso, os itens de conhecimento dos processos e da cultura organizacional, presentes no fator de Integração à Organização indicam, de certa forma, um acolhimento dos padrões organizacionais. Por esta razão, supõe-se que a orientação tradicional da sociedade brasileira, que enfatiza o respeito à autoridade e a conformidade social (INGLEHART; WEZEL, 2005), pode estar reforçando os comportamentos de aceitação e conformidade ao status quo, por parte dos servidores da universidade brasileira, contribuindo para que estes se percebam como mais integrados à organização.

Outro aspecto que deve ser considerado, na análise geral dos dados, diz respeito às diferenças que podem estar ocorrendo nos resultados de socialização entre os servidores de diferentes ocupações (docentes e técnicos administrativos) nas duas universidades estudadas. Assim, no intuito de verificar a ocorrência de diferenças significativas nos resultados de socialização organizacional em função, não somente da nacionalidade, mas também da ocupação, foram realizados testes ANOVA. Em conformidade com os procedimentos recomendados por Dancey e Reidy (2006) e Tabachnick e Fidell (2007) para a condução dos testes, observou-se primeiramente a magnitude da correlação existente entre as variáveis dependentes (neste caso, representadas pelos fatores de socialização organizacional).

Dada a elevada correlação constatada entre estes fatores (coeficientes de correlação de Pearson oscilando entre 0,25 e 0,71 ), optou-se por estimar um escore médio total para o ISO e empregá-lo como variável dependente em um teste ANOVA 2x2, no qual entraram como variáveis independentes a nacionalidade e a ocupação. Tal estratégia objetivou evitar a obtenção de resultados equivocados que, de acordo com aqueles autores, podem ocorrer quando se empregam variáveis dependentes altamente correlacionadas em vários testes ANOVA ou em um teste MANOVA.

Os resultados obtidos apontaram a existência de um efeito principal significativo para a ocupação $(\mathrm{F}=5,73 ; \mathrm{p}=0,02)$, com professores em geral $(\mathrm{M}=4,23 / \mathrm{D} . \mathrm{P} .=0,49)$ se mostrando 
mais bem socializados do que funcionários técnico-administrativos (M=4,03/D.P.=0,43). Para a nacionalidade, entretanto, o efeito principal não foi significativo $(\mathrm{F}=0,78 ; \mathrm{p}=0,38)$.

Quanto ao efeito interativo observado entre nacionalidade e ocupação ( $F=7,04$; $\mathrm{p}=0,009$ ) e ilustrado na Figura 1 , tem-se que a diferença nos resultados de socialização organizacional entre as duas ocupações na universidade brasileira foi significativamente maior do que na universidade norueguesa.

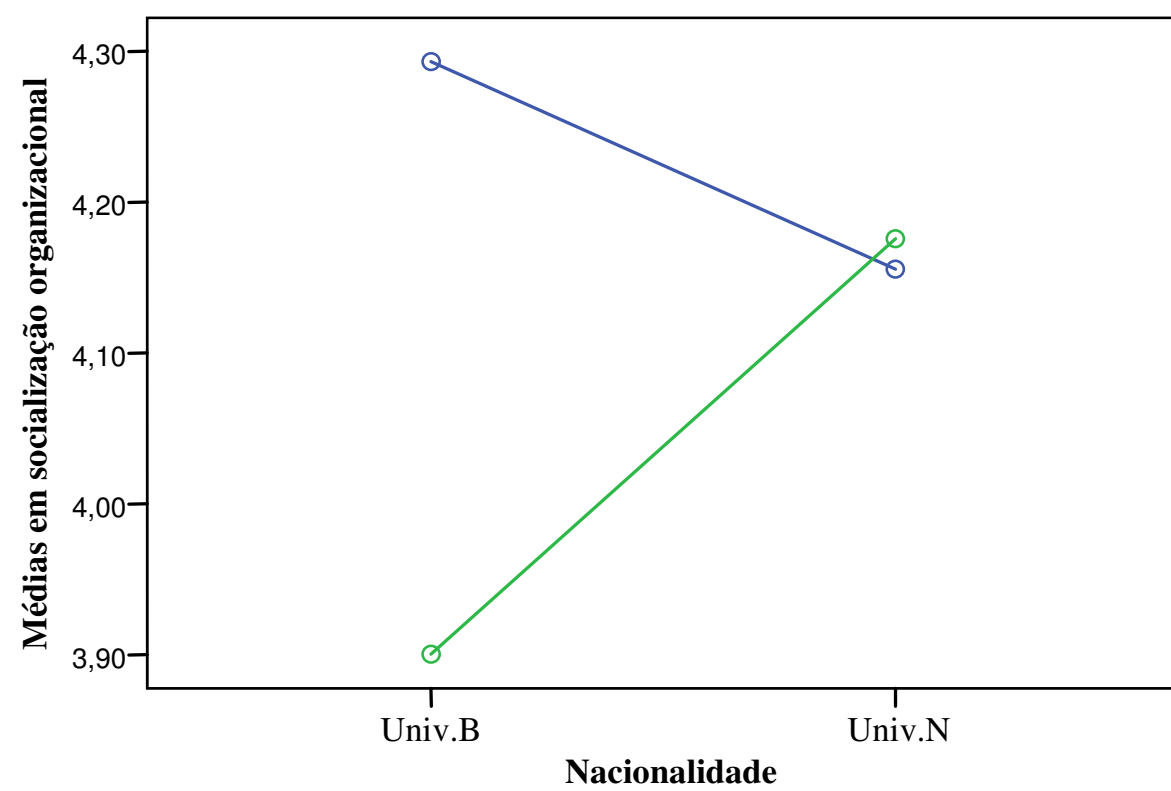

Ocupação:

- Docente

- Funcionário técnicoadministrativo

Nota: Univ.B = Universidade brasileira / Univ. $\mathrm{N}=$ Universidade Norueguesa

Figura 1 - Efeito interativo entre nacionalidade e ocupação nos resultados de socialização

Fonte: autores

Além disso, a análise da Figura 1 mostra que melhores resultados de socialização organizacional, por parte de servidores docentes em comparação aos técnico-administrativos, só se confirmaram para o caso da universidade brasileira. Na instituição norueguesa, estes se mostraram bem próximos entre as duas categorias ocupacionais.

Tal diferença de socialização entre as ocupações na universidade brasileira, que se caracteriza por uma maior dificuldade de parte dos novos servidores técnico-administrativos, pode estar relacionada à maior rotatividade dos mesmos, a qual foi identificada com base em consulta aos dados do Departamento de Pessoal da referida instituição (DAP, comunicação pessoal, outubro, 2009). Estes dados indicavam que a rotatividade entre novos servidores 
Socialização organizacional: estudo comparativo entre servidores públicos brasileiros e 362 noruegueses

técnico-administrativos (com menos de três anos de serviço na instituição) foi de 14,4\%, sendo quase três vezes maior do que a de novos servidores docentes $(5,6 \%)$.

Conforme discutido anteriormente, um dos resultados distais de uma socialização bem sucedida é a intenção de permanecer no emprego (SAKS; ASHFORTH, 1997; ALLEN, 2006; COOPER-THOMAS; ANDERSON, 2006), ao passo que problemas na socialização podem ocasionar aumento da rotatividade. Portanto, a maior rotatividade dos novos servidores técnico-administrativos pode ser um resultado distal da socialização organizacional naquela instituição, o qual estaria sendo promovido a partir das deficiências nos resultados proximais de socialização. Tais deficiências são aqui representadas por dificuldades no Acesso às Informações, menor percepção de Competência e Pró-atividade, menor Integração às Pessoas e à Organização, e menor conhecimento e identificação com os Objetivos e Valores Organizacionais.

Isso implica em grandes prejuízos para a instituição, não somente pela perda do investimento realizado no processo de recrutamento, seleção e treinamento, haja vista os recursos despendidos na realização de concursos e atividades de capacitação, mas também pelo período decorrido entre o recrutamento e seleção de um novo servidor, até que a vaga seja novamente preenchida e este se encontre devidamente capacitado para o desempenho das funções requeridas em seu posto.

Cumpre notar, ainda, que os resultados de socialização organizacional tenderam a ser melhores entre os funcionários técnico-administrativos da universidade norueguesa em comparação aos da universidade brasileira. O contrário ocorreu entre os docentes, isto é, os resultados de socialização destes tenderam a ser mais satisfatórios entre os brasileiros em comparação aos servidores noruegueses. Tais resultados denotam, portanto, que o efeito da nacionalidade sobre a socialização organizacional dependeu do grupo ocupacional a que os novos servidores pertenciam e que a homogeneidade nos resultados de servidores docentes e técnico-administrativos foi verificada somente na universidade norueguesa.

Entende-se que tais achados podem ser um indicador da adoção de práticas sociais mais equitativas pelos noruegueses, e mais desiguais pelos brasileiros, nas relações de trabalho. Um aspecto cultural que pode estar contribuindo para tal diferença é aquele relativo à distância de poder. Nas situações de trabalho em sociedades em que a distância de poder é menor, como é o caso da Noruega, verifica-se uma relação de maior igualdade entre os ocupantes de diferentes cargos (HOFSTEDE; HOFSTEDE, 2005), a qual pode estar se 
refletindo numa maior homogeneidade de socialização entre servidores docentes e técnicoadministrativos noruegueses.

Corroborando a diferença aqui identificada nos resultados de socialização entre professores e servidores técnico-administrativos na universidade brasileira, estudo anterior acerca da socialização organizacional dos servidores (OLIVEIRA et al., 2008), nessa mesma instituição, já havia verificado que comparativamente aos funcionários técnicoadministrativos, os docentes tendiam a relatar mais acesso à informação; a se considerar mais competentes e pró-ativos; mais integrados às pessoas; e, com maior clareza quanto aos objetivos e valores organizacionais.

Retomando o aspecto cultural relativo à distância de poder, mais elevado na sociedade brasileira, vale salientar que a distribuição de recursos tende a retratar as desigualdades na distribuição de poder (HOFSTEDE; HOFSTEDE, 2005). Tais recursos, usualmente entendidos como recompensas financeiras, também envolvem a detenção de conhecimento e informação, haja vista a relação positiva, normalmente verificada, entre ambos. É nesse sentido que a maior distância de poder pode estar contribuindo para um menor acesso às informações e um menor conhecimento dos objetivos, valores, linguagem e tradição organizacionais, dentre outros aspectos, entre os servidores técnico-administrativos da universidade brasileira.

Além disso, no que concerne à política salarial, desigualdades entre os ocupantes de diferentes cargos no Brasil estão presentes no serviço público e a realidade das universidades segue, em parte, esta tendência. Os aumentos concedidos, recentemente, aos servidores técnico-administrativos ${ }^{3}$ diminuíram um pouco a profundidade desta desigualdade, mas ela provavelmente continua existindo, principalmente do ponto de vista cultural, na forma das atitudes e condutas socialmente construídas, se manifestando também sob a forma de maiores dificuldades no processo de socialização organizacional por parte dos servidores técnicoadministrativos brasileiros, conforme verificado.

Importa resgatar aqui as considerações de Cooper-Thomas e Anderson (2006), anteriormente apresentadas, acerca dos benefícios que podem advir de uma socialização bem sucedida, dentre elas: a minimização do desencontro de expectativas entre trabalhador e

\footnotetext{
${ }^{3}$ No período de 2003 a 2007, a categoria de servidores técnico-administrativos acumulou reajustes de 82,3\% a 175,2\%, sendo que para os docentes os reajustes variaram entre $47 \%$ a $141,48 \%$. A nova tabela salarial, implementada a partir de 2008 , prevê percentuais de aumento da ordem de $35,8 \%$ a $105,4 \%$ para servidores técnico-administrativos e de $9,9 \%$ a $59 \%$ para docentes.

Maiores informações: http://www.planejamento.gov.br/noticia.asp?p=not\&cod=1812\&cat=26\&sec=11

REAd I Porto Alegre - Edição 72 - N 2 - maio/agosto 2012 - p. 339-371
} 
Socialização organizacional: estudo comparativo entre servidores públicos brasileiros e 364 noruegueses

organização, a identificação dos critérios de desempenho em nível individual e organizacional e o conhecimento dos valores, normas, redes de recursos e políticas da organização. E também a observação de Chao et al. (1994) de que, geralmente, as pessoas bem socializadas em seus papéis organizacionais têm maiores rendimentos pessoais, mais satisfação, envolvimento com suas carreiras, adaptabilidades e senso de identidade pessoal do que as que são menos socializadas. Deve-se, portanto, refletir sobre as perdas que podem estar sendo geradas para os servidores técnico-administrativos e para a universidade estudada, em virtude das dificuldades comparativas de socialização por parte dos mesmos, numa busca por superar as deficiências identificadas.

\section{Considerações Finais}

O presente artigo enfocou a socialização organizacional de novos servidores em instituições públicas de ensino superior, a partir da abordagem de um conjunto de aspectos relevantes para a adaptação e atuação proficiente de um indivíduo no trabalho. Considerando que as especificidades presentes em contextos culturais e socioeconômicos distintos podem influenciar as condições de socialização organizacional, o estudo foi delineado com vistas a uma comparação dos resultados de tal processo entre trabalhadores de duas universidades, sendo uma brasileira e outra norueguesa.

Com base nos achados obtidos, foi possível traçar os perfis de socialização dos dois grupos de servidores e analisar as possíveis influências de características culturais nos resultados. Observou-se, por exemplo, que os servidores noruegueses, de modo geral, relataram maior integração às pessoas do que os servidores brasileiros e estes, por sua vez, tenderam a resultados mais satisfatórios de integração à organização. Notou-se, ainda, que a nacionalidade e a ocupação exerceram um efeito interativo na socialização organizacional, de forma que os funcionários técnico-administrativos noruegueses tenderam a se mostrar mais socializados do que os brasileiros e entre estes últimos, os docentes demonstraram uma socialização mais satisfatória comparativamente aos noruegueses. Além disso, uma homogeneidade nos resultados de servidores docentes e técnico-administrativos foi verificada somente na universidade norueguesa, sendo expressivas as diferenças na socialização dos servidores, em ocupações distintas, na universidade brasileira, caracterizada por uma maior dificuldade de parte dos novos servidores técnico-administrativos. 
A constatação de maior rotatividade entre tais servidores corrobora a noção, defendida na literatura de socialização organizacional, de que resultados proximais de socialização insatisfatórios, aqui representados pela dificuldade no Acesso às Informações, menor percepção de Competência e Pró-atividade, menor Integração às Pessoas e à Organização, e menor conhecimento e identificação com os Objetivos e Valores Organizacionais, geram impactos nos resultados distais, sendo um deles a intenção de deixar o emprego (SAKS; ASHFORTH, 1997; ALLEN, 2006; COOPER-THOMAS; ANDERSON, 2006). Destacam-se os prejuízos para a instituição, gerados por tal deficiência de socialização, salientando não somente a perda do investimento realizado no processo de recrutamento, seleção e treinamento, como também o período demandado até que um novo servidor assuma o posto e possa atuar com proficiência no desempenho das funções requeridas.

Atentando para os diferentes contextos culturais em que se inserem as duas universidades aqui estudadas, refletiu-se que a maior integração às pessoas, entre os servidores noruegueses, poderia vir a fortalecer considerações, anteriormente tecidas na literatura, a respeito da existência de traços coletivistas na cultura norueguesa (TRIANDIS, 1995; BIAGGIO; VIKAN; CAMINO, 2005) e da possibilidade de que o individualismo e o coletivismo, como dimensões independentes, possam coexistir no mesmo grupo e variar de acordo com as situações (KÂĞITÇIBAŞI, 1994). Não se descartou também o papel que o maior nível de confiança interpessoal existente na Noruega, em comparação ao Brasil, poderia estar desempenhando em termos de facilitação das relações sociais entre aqueles servidores.

No que diz respeito aos resultados de maior integração à organização por parte dos servidores brasileiros, duas considerações acerca de possíveis influências culturais foram propostas, considerando que podem ter contribuído para tal resultado: a evitação de incerteza, mais elevada na sociedade brasileira, do que na norueguesa; e a orientação tradicional (em oposição à secular e racional), característica do Brasil.

Quanto à homogeneidade nos resultados de socialização entre servidores docentes e técnico-administrativos, verificada apenas na universidade norueguesa, cogitou-se a possibilidade de que a menor distância de poder, típica daquela sociedade, estivesse contribuindo para a adoção de práticas sociais mais equitativas, nas relações de trabalho. Reflexões como essas suscitam, por si, a realização de novos estudos, com outras técnicas de coleta de dados, como entrevistas e grupos focais, para explorar tais possibilidades. Além disso, a utilização de escalas para mensuração da orientação cultural, no nível individual, 
Socialização organizacional: estudo comparativo entre servidores públicos brasileiros e 366 noruegueses

pode contribuir para fornecer informações mais precisas acerca dos impactos da orientação cultural sobre os resultados da socialização organizacional.

Identificam-se, portanto, novas oportunidades de estudo, inclusive no sentido de proporcionar um levantamento de informações em diferentes instituições públicas no Brasil, verificando até que ponto esta tendência à manutenção de desigualdades mais profundas na relação entre os membros organizacionais (distância de poder) tende a ser replicada. Residem, nos aspectos acima citados, algumas das limitações do presente estudo, as quais não permitiram, por exemplo, tecer inferências mais seguras acerca do papel das diferenças culturais nos resultados da socialização organizacional. Outras limitações que se deve ter em mente ao interpretar e aplicar os resultados aqui discutidos dizem respeito ao tamanho da amostra, que pode não ter sido suficiente para garantir a representatividade das respectivas populações, e ao número reduzido de categorias ocupacionais envolvidas.

A despeito dessas limitações, todavia, o trabalho prestou algumas importantes contribuições. As diferenças verificadas na socialização organizacional de novos servidores pertencentes a diferentes categorias ocupacionais se constitui em um alerta às organizações que podem estar refletindo em suas práticas de gestão uma orientação cultural voltada à manutenção de desigualdades mais profundas na relação entre os membros organizacionais. Cumpre buscar ferramentas que possam corrigir ou minimizar as distorções provocadas por tais práticas, como a adoção de programas de tutorização formal, os quais podem representar uma alternativa nesse sentido.

No que tange aos iniciantes que estejam assumindo empregos em contextos culturais distintos, o presente estudo também apresenta algumas reflexões referentes a implicações potenciais. As organizações que recebem iniciantes provenientes de países caracterizados por orientações culturais distintas precisam estar conscientes dessas questões e preparadas para lidar com tais circunstâncias. Implica também a necessidade de que os indivíduos que venham a assumir empregos em organizações sediadas em países de culturas distintas aprendam sobre as mesmas, buscando se adaptar às expectativas.

Salienta-se, por fim, que embora os achados aqui obtidos forneçam apenas algumas pistas acerca da importância da orientação cultural sobre os resultados de socialização nas organizações, estes constituem uma indicação de que tal temática merece ser apreciada nas pesquisas, razão pela qual se espera que as reflexões aqui desenvolvidas possam orientar o desenvolvimento de futuras pesquisas no tema. 


\section{REFERÊNCIAS}

ADKINS, C. L. Previous work experience and organizational socialization: a longitudinal examination. Academy of Management Journal, v. 38, n. 3, p. 839-862, 1995.

ALLEN, D. G. Do organizational socialization tactics influence newcomer embeddedness and turnover? Journal of Management, v. 32, n. 2, p. 237-256, 2006.

ASHFORD, S. J.; BLACK, J. S. Proactivity during organizational entry: the role of desire for control. Journal of Applied Psychology, v. 81, n. 2, p. 199-214, 1996.

ASHFORTH, B. E.; SLUSS, D. M.; SAKS, A. M. Socialization tactics, proactive behavior and newcomer learning: integrating socialization models. Journal of Vocational Behavior, v. 70, n. 3, p. 447-462, 2007.

AYCAN, Z.; KANUNGO, R. N. Cross-cultural industrial and organizational psychology: a critical appraisal of the field and future directions. In: NEIL, A. et al. (Orgs.). Handbook of industrial, work and organizational psychology. London: Sage, 2001. p. 385-408.

BACHMAN, J. G.; O’MALLEY, P. M. Yea saying, nay saying, and going to extremes: black-white differences in response styles. Public Opinion Quarterly, v. 48, n. 2, p. 491-509, 1984.

BAUER, T. N. et al. Newcomer adjustment during organizational socialization: a metaanalytic review of antecedents, outcomes, and methods. Journal of Applied Psychology, v. 92, n.3, p. 707-721, 2007.

BAUER, T. N.; TAYLOR, S. Toward a globalized conceptualization of organizational socialization. In: NEIL, A. et al. (Orgs.). Handbook of industrial, work and organizational psychology. London: Sage, 2001. p. 409-423.

BIAGGIO, A.; VIKAN, A.; CAMINO, C. Orientação social, papel sexual e julgamento moral: uma comparação entre duas amostras brasileiras e uma norueguesa. Psicologia: Reflexão e Crítica, v. 18, n. 1, p.1-6, 2005.

BORGES, L. O.; ALBUQUERQUE, F. J. B. Socialização organizacional. In: ZANELLI, J. C.; BORGES-ANDRADE, J. E.; BASTOS, A. V. B. (Orgs.) Psicologia, organizações e trabalho no Brasil. Porto Alegre: Artmed, 2004. p. 331-356.

BORGES, L. O. et al. Re-construção e validação de um inventário de socialização organizacional. Revista de Administração Mackenzie, v. 11, n. 4, p. 4-37, 2010. 
Socialização organizacional: estudo comparativo entre servidores públicos brasileiros e 368 noruegueses

CARR, J. C. et al. Prior occupational experience, anticipatory socialization, and employee retention. Journal of Management, v. 32, n. 3, p. 343-359, 2006.

CARVALHO, V. Resiliência e socialização organizacional de novos servidores: um estudo transcultural. Tese de doutorado. Universidade Federal do Rio Grande do Norte, Natal, RN. Brasil.

CHAO, G. et al. Organizational socialization: its content and consequences. Journal of Applied Psychology, v. 79, n. 5, p. 730-743, 1994.

COOPER-THOMAS, H. D.; ANDERSON, N. Organizational socialization: a new theoretical model and recommendations for future research and HRM practices in organizations. Journal of Managerial Psychology, v. 21, n. 5, p. 492-516, 2006.

DANCEY, C. P.; REIDY, J. Estatística sem matemática para psicologia. Porto Alegre: Artmed, 2006.

FELDMAN, D. C. The multiple socialization of organizational members. Academy of Management Review, v. 6, n. 2, p. 309-318, 1981.

FELDMAN, D. C.; BRETT, J. M. Coping with new jobs: a comparative study of new hires and job changers. Academy of Management Journal, v. 26, n. 2, p. 258-272, 1983.

FINKELSTEIN, L. M.; KULAS, J. T.; DAGES, K. D. Age differences in proactive newcomer socialization strategies in two populations. Journal of Business and Psychology, v. 17, n. 4, p. 473-502, 2003.

FREITAS, M. N. C. Organização escolar e socialização profissional de professores iniciantes. Cadernos de Pesquisa, n. 115, p. 155-172, 2002.

FREITAS, M. N. C. et al. Socialização organizacional de pessoas com deficiência. Revista de Administração de Empresas, v. 50, n. 3, p. 264-275, 2010.

GOUVEIA, V. V. et al. Human values and social identities: a study in two collectivist cultures. International Journal of Psychology, v. 37, n. 3, p. 333-342, 2002.

GRIFFIN, A. E. C.; COLELLA, A.; GOPARAJU, S. Newcomer and organizational socialization tactics: an interactionist perspective. Human Resource Management Review, v. 10, n. 4, p. 453-474, 2000. 
HAUETER, J. A.; MACAN, T. H.; WINTER, J. Measurement of newcomer socialization: construct validation of a multidimensional scale. Journal of Vocational Behavior, v. 63, n. 1, p. 20-39, 2003.

HERK, H.; POORTINGA, Y. H.; VERHALLEN, T. M. M. Response styles in rating scales: evidence of method bias in data from six EU countries. Journal of Cross-cultural Psychology, v. 35, n. 3, p. 346-360, 2004.

HOFSTEDE, G. et al. Measuring organizational cultures: a qualitative and quantitative study across twenty cases. Administrative Science Quarterly, v. 35, n. 2, p. 286-316, 1990.

HOFSTEDE, G.; HOFSTEDE, G. J. Cultures and organizations: software of the mind. New York: McGraw-Hill, 2005.

HUI, C. H.; TRIANDIS, H. C. Effects of culture and response format on extreme response style. Journal of Cross-cultural Psychology, v. 20, n. 3, p. 296-309, 1989.

INGLEHART, R.; BAKER, W. E. Modernization, cultural change, and the persistence of traditional values. American Sociological Review, v. 65, n. 1, p. 19-51, 2000.

INGLEHART, R.; WELZEL, C. Modernization, cultural change and democracy: the human development sequence. New York: Cambridge University Press, 2005.

INGLEHART, R. et al. Development, freedom, and rising happiness. a global perspective (1981-2007). Perspectives on Psychological Science, v. 3, n. 2, p. 264-285, 2008.

JONES, G. R. Psychological orientation and the process of organizational socialization: an interactionist perspective. Academy of Management Review, v. 8, n. 3, p. 464-474, 1983.

JONES, G. R. Socialization tactics, self-efficacy, and newcomers' adjustments to organizations. Academy of Management Journal, v. 29, n. 2, p. 262-279, 1986.

KÂĞITÇIBAŞI, C. A critical appraisal of individualism and collectivism: toward a new formulation. In: KIM, U. et al. (Orgs.). Individualism and collectivism: theory, method and applications. Thousand Oaks: Sage publications, 1994. p. 52-65.

KISH, L. Diseño estadístico para la investigación. Madri: Siglo Veintiuno de España Editores, 1996. 
Socialização organizacional: estudo comparativo entre servidores públicos brasileiros e 370 noruegueses

LISBONA, A.; MORALES, J. F.; PALACÍ, F. J. Engagement as a consequence of organizational socialization. International Journal of Psychology \& Psychological Therapy, v. 9, n. 1, p. 89-100, 2009.

LOUIS, M. R. Surprise and sense making: what newcomers experience in entering unfamiliar organizational settings. Administrative Science Quarterly, v. 25, n. 2, p. 226-251, 1980.

MAJOR, D. A.; KOZLOWSKI, S. W. J. Newcomer information seeking: individual and contextual influences. International Journal of Selection and Assessment, v. 5, n. 1, p. 16-28, 1997.

MILLER-LOESSI, K.; PARKER, J. N. Cross-cultural social psychology. In: DELAMATER, J. (Org). Handbook of social psychology. New York: Springer, 2006. p. 529-553.

MORRISON, E. W. Longitudinal study of the effects of information seeking on newcomer socialization. Journal of Applied Psychology, v. 78, n. 2, p. 173-183, 1993a.

MORRISON, E. W. Newcomer information seeking: exploring types, modes, sources, and outcomes. Academy of Management Journal, v. 36, n. 3, p. 557-589, $1993 \mathrm{~b}$.

MORRISON, E. W. Information usefulness and acquisition during organizational encounter. Management Communication Quarterly, v. 9, n. 2, p. 131-155, 2005.

NELSON, D. L. Organizational socialization: a stress perspective. Journal of Occupational Behavior, v. 8, n. 4, p. 311-324, 1987.

OLIVEIRA et al. A socialização organizacional segundo grupo ocupacional e tempo de serviço. Revista Psicologia: Organizações e Trabalho, v. 8, n.1, p. 118-141, 2008.

OSTROFF, C.; KOZLOWSKI, S. W. J. Organizational socialization: the role of information acquisition. Personnel Psychology, v. 45, n. 4, p. 849-872, 1992.

REICHERS, A. E. An interactionist perspective on newcomer socialization rates. Academy of Management Review, v. 12, n. 2, p. 278-287, 1987.

ROS, M.; GOUVEIA, V. V. Validade dos modelos transculturais sobre os valores. In: ROS, M.; GOUVEIA, V. V. (Orgs.). Psicologia social dos valores humanos: desenvolvimentos teóricos, metodológicos e aplicados. São Paulo: Senac, 2006. p. 207-235. 
SAKS, A. M. Moderating effects of self-efficacy for the relationship between training method and anxiety and stress reactions of newcomers. Journal of Organizational Behavior, v. 15, n. 7, p. 639-654, 1994.

SAKS, A. M. Longitudinal field investigation of the moderating and mediating effects of selfefficacy on the relationship between training and newcomer adjustment. Journal of Applied Psychology, v. 80, n. 2, p. 211-225, 1995.

SAKS, A. M.; ASHFORTH, B. E. Organizational socialization: making sense of past and present as a prologue for the future. Journal of Vocational Behavior, v. 51, n. 2, p. 234-279, 1997.

SARRIÁ, A.; GUARDIÃ, J.; FREIXA, M. Introducción a la estadística em Psicologia. Barcelona: Ediciones de la Universitat de Barcelona, 1999.

SCARPARO, H. Psicologia e pesquisa. Porto Alegre: Sulina, 2000.

SHINYASHIKI, G. O processo de socialização organizacional. In: FLEURY, M. T. L. (Org.). As pessoas na organização. São Paulo: Editora Gente, 2002. p. 165-184.

SMITH, P. B.; BOND, M. H.; KÂĞITÇIBAŞI, C. Understanding social psychology across cultures: living and working in a changing world. London: Sage, 2006.

TABACHNICK, B. G.; FIDELL, L. S. Using multivariate statistics. Boston: Pearson, 2007.

TAORMINA, R. J. Organizational socialization: a multidomain, continuous process models. International Journal of Selection and Assessment, v. 5, n. 1, p. 29-47, 1997.

TRIANDIS, H. C. The self and social behavior in differing cultural contexts. Psychological Review, v. 96, n. 4, p. 506-520, 1989.

TRIANDIS, H. C. Culture and social behavior. New York: McGraw-Hill, 1994.

TRIANDIS, H. C. Individualism and collectivism. Boulder, CO: Westview Press, 1995.

VAN MAANEN, J.; SCHEIN, E. H. Toward a theory of organization socialization. Research in Organizational Behavior, v. 1, p. 209-264, 1979.

WANBERG, C. R.; KAMMEYER-MUELLER, J. D. Predictors and outcomes of proactivity in the socialization process. Journal of Applied Psychology, v. 85, n. 3, p. 373-385, 2000.

REAd I Porto Alegre - Edição 72 - Nº 2 - maio/agosto 2012 - p. 339-371 